\title{
MARKET RISK AND RETURNS: EVIDENCE FROM THE NIGERIAN CAPITAL MARKET
}

I. O. OSAMWONYI AND E. I. ASEIN

(Received 30 April 2007; Revision Accepted 3, July 2007)

\section{ABSTRACT}

The relationship befween market returns proxied by 'botas' and security returns is well established in the relevant extant literature. The objective of this paper is to provide evidence that this relationship holds in the Nigerian Capital Market. The study specifically examines market risk as defined in the Capital Asset Pricing Model (CAPM) as an explanatory variable for security returns in the Nigerian Capital Market. The model was tested with quafterly data for the period 2001 to 2005, using the most capitalized firms in the Nigerian Capital market. The findings confirm a positive linear relationship between market betas and security returns for the sampled Nigerian firms.

KEWWORDS: Capital Asset Pricing Model, Betas JEL Classification: G11, G12

\section{INTRODUCTION}

The Capital Asset Pricing Model (CAPM) developed independently by many writers such as Sharpe (1964) and Lintner (1965) marks the birth of asset pricing theory. This theory is widely applied today, influencing the decisions of bankers, brokers, government agencies, and millions of investors world-wide. Their work explained how the weighing of risk and reward helps to determine securities prices; and how those prices depend on such factors as tax changes and bankruptcy risk (UW Showcase, 1997). Markowitz (1952) had focused on how investors use risk and return assessments in forming portfolios. His paper emphasized that diversineation is required to obtain the optimal tradeoff between risk and return. Sharpe (1964), built on that work by developing the CAPM which explains how markets incorporate risk in miging securities.

Before the breakthrough, there were no asset pricing models with clear testable predictions about risk and retum. According to Fama and French (2003). "the attraction of the CAPM is its powerful simple logic and intuitively pleasing predictions about how to measure risk and about the relation between expected return and risk". In aboul four decades after, the CAPM is still widely used in applications; such as estimating the cost of equity capital for firms and evaluating the performance of managed porfolio (Burton, 1998, and Fama and French, 2003)

Most assets that we choose to invest in, financial as well as real have some exposure to risk. Financial theory and common sense tell us that those investments that are riskier require higher risk premium. Post-Markowitz (1952) models using risk-return parameters take the view that the relevant risk in an investment should be the risk perceived by a well diversified investor, and that the expected return should be a function of this risk measure 'beta'. At one end, the capital asset pricing model measures the market risk with a beta [measured relative to a market portfolio]. and at the end are multi-factor models that measure market risk using multiple betas estimated relative to different factors. The classical portfolio theory says that investors are risk averse and choose a portfolio with maximum risk adjusted retum. Capital Asset Pricing Model (CAPM) gives the relationship between risk and expected return for a security.

Empirical tests of the CAPM in developed countries have had mixed results; security returns do appear to be positively related to their respective measured market 'betas', but not in the precise manner implied by the model (Elton and Gruber, 1997). Against this background, the study attempts to examine within CAPM the relationship between market risk proxied by beta and security returns using empirical evidence from the Nigerian Capital Market.

\section{REVIEW OF RELATED LUTERATURE:}

Investors base their investment decision on the expected return and risk of investments (Kevin, 2001). Risk is measured by the variability in returns and investors attempt to reduce that variability through the diversification of their investments. This results in the creation of portfolios from an infinite set of securities or assets. Among the portfolios, some are efficient while some are not. Investors identify the efficient set of portfolio using the rule of maximizing expected return at a given risk level or minimizing expected risk given a return level. Diversification heips to reduce risk, but even a welldiversified portfolio does not become risk free (Markowitz. 1952; Kevin, 2001). Each diversified portfolio is still subject to variability which is not diversifiable known as systematic risk [beta risk]. A rational investor would expect the return on a security to be commensurate with this risk. Thus, the CAPM gives the relationship between the expected return and the systematic risk of a security (Kerr, 1997).

\section{The Capital Asset Pricing Model}

The Capital Asset Pricing Model (CAPM) is an conomic model for valuing stocks, securities, derivatives and/or assets by relating risk and expected retum. It is an equilibrium model, which describes the pricing of assets as well as derivatives. Van Horne (2004), defines the CAPM Model as an equilibrium model of the trade-off between expected portfolio return and unavoidable risk. Kevin (2001), describes the CAPM Model as the relationship between risk and return established by the security market line. It is basically a simple linear relationship. The higher the value of bata, the higher would be the risk of the security and therefore the larger would be the return expected by the investors. In other words, all securities are expected to yield returns commensurate with their riskiness as measured by beta. This relationship is valid not only for individual securities, but is also for all portfolios whether efficient or inefficient. According to Riskglossary (2006:2),

"We call CAPM a 'capital asset pricing model' because, given a beta and an expected return for an asset, investors will bid its current price up or down, adjusting that expected return so that it satisfies the 
formula. Accordingly, the CAPM predicts the equilibrium price of an asset; this works because the model assumes that all investors agree on the beta and expected return of any asset..."

The Security Market Line [SML] provides the relationship beween the expected return and beta of a security or portfolio. It deseribes the risk return relationship for all portfolios as well as individual securities. Osaze (2000) states that the SML "is the expected linear relationship between the return and the systematic risk for a security and the market". "The security market line provides a standard for project acceptance. If the project return lies above the security market line, then the return is higher than investors could expect to get by investing their funds in the capital market and therefore is an attractive investment opportunity (Berkley, et al, 2001). SML is express thus

$$
\begin{aligned}
E(R p) & =R f+[E(R m)-R f] / \sigma m \\
& \left.=R f+\text { Cov }_{m}[E(R m)-R f)\right]
\end{aligned}
$$

$$
\sigma^{2} \mathrm{~m}
$$

Defining $\operatorname{Cov}_{m} / \sigma^{2}$ as Beta ( $\beta$ ), this equation can be stated: $E(R p)=R f+\beta[E(R m)-R f]$.

The CAPM is based on the idea that investors demand additional expected return (more risk premium) if they are asked to accept additional risk. The C.APM model says that this expected return that these investors would demand is equal to the rate on a risk-free security plus a risk premium. If the expected return does not meet/beat the required return, the investors will refuse to invest.

The classical portfolio theory says that investors are risk averse and choose a portfolio with maximum risk adjusted return. Capital Asset Pricing Model (CAPM) gives the relationship between risk and expected return for a security. If all investors are assumed willing to optimize their expected return adjusted for risk, every efficient portfolio will lie on the CML [which shows the trade off between expected return and risk]. The CML is graphically presented below in Fig.1.

Fig. 1 Security Market Line

Expocted return

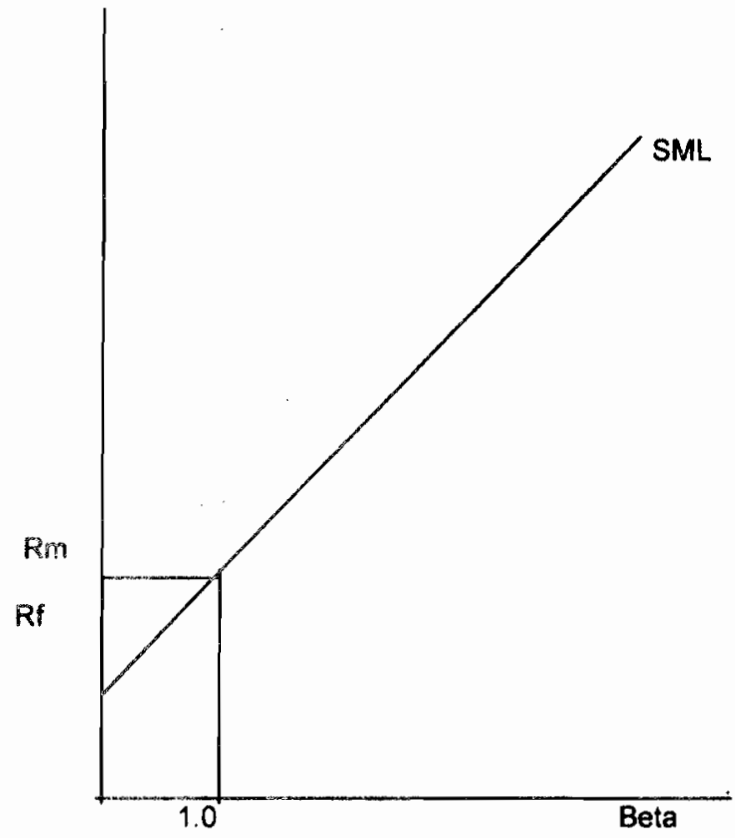

Priging of Securities with CAPM

CAPM can be used for pricing of securities whether underpriced, overpriced or correctly priced. According to CAPM, each security is expected to provide a return commensurate with its level of risk (Kevin, 2001). A security may be offering more return than the expected return, making it more attractive. On the contrary, another security may be offering less return than the expected return, making it less attractive. If the expected return on a security calculated using the CAPM is lower than the actual or estimated return offered by the security, the security will be considered to be underpriced. On the contrary, a security will be considered to be overpriced when the expected return on the security according to CAPM formulation is higher than the actual return offered by the security (Kevin, 2001). Thus, in the context of the security market line, securities that plot above the line presumably are underpriced because they offer a higher return than that expected from securities with the same risk. On the other hand, a security is presumably overpriced if it plots below the SML. because it is estimated to provide a lower return than that expected from securities in the same risk class (Kevin, 2001).

CAPM is only valid within a special set of assumptions, which are:

- Investors are risk averse individuals who maximize the expected utility of their end of period wealth, thus it is a one period model. An investor will maximize expected utility of his end of period wealth where his subjective marginal rate of substitution between risk and return represented by his indifference curves is equal to the objective marginal rate of transformation offered by the minimum variance opportunity set.

- Investors have homogenous expectations about asset returns and therefore have identical opportunity sets.

- Asset returns are described by the normal distribution, i.e. they are described completely by its two parameters: mean value $(\mu)$ and variance $\left(\sigma^{2}\right)$.

There exists a risk free asset and investors may borrow or lend unlimited amounts of this asset at a constant rate: the risk free rate. 
- There are a definite number of assets and their quantities are fixed within the one period world:

- All assets are perfectly divisible and priced in a perfectly competitive market, thus effectively excluding human capital. This also means that asset markets are frictionless and information is costless and simultaneously available to all investors. There are no market imperfections such as taxes, regulations, or restrictions on short selling.

Although the assumptions mentioned above normally are not all valid, CAPM remains one of the most used investments valuation model and tends to perform well empirically. The assumptions have been criticized as unrealistic assumptions such perfect market, homogenous expectations, absence of transaction costs and taxes, normal distributions, unlimited lending and borrowing at the same riskfree rate, one factor [beta] and single period, and its exante nature (Moine, 2004). Although CAPM is not perfect, it is probably a fairly good predictor of retum and is certainly better than anything else that is available. Since we yet to see a better theory that is significantly different, we continue to use the CAPM, being wary of all the estimation problems.

\section{Empirical Tests}

Tobin (1958), Sharpe(1964) and Lintner (1965) know like everyone else that investor hold different beliefs, that borrowing rates are typicaliy higher than lending rates and there is credit restriction on the amount that can be borrowed. Thus, they have been criticized for leaving the empirical validation of their conclusions to others. By relaxing the assumptions involved in the derivation of the CAPM, the model has been extended to more general conditions, usually at the expense of simplicity in the structure of equilibrium expected return (Fama and French, 2003; Sharpe et al, 2006).

Empirical tests of the CAPM have relied on proxies for the market portiolio. Efforts have been on the ability of the model to capture total systematic risk, the stationarity of beta, and its ability to explain difference in observed and expected returns. Results on test of CAPM based on individual securities have been mixed. CAPM is in terms of investor's expectations, yet tests used realized ex-post returns. The different between realized and expected return is the residual term that should be zero on average if model is correctly specified. If CAPM is correct, the regression of returns against beta should result in a positive slope equal to the average market risk premium (Rm - Rf) and intercept at average Rf. Some tests show larger betas securities have higher rates of retum and that the relationship between betas and the returns are linear. Others indicated that the slope was lower than predicted and intercept higher. For detail survey, see Elton and Gruber (1997).

To deal with measurement errors for individual estimates (some too high, some too low), portfolios were adopted. Results indicated that the slope of the relationship between beta and the returns was positive but lower and the intercept less than averaged (Elton and Gruber, 1997). Results indicate that the stationarity of beta is related to number of securities in the portfolio, the length of period used for beta estimation, length of holding periods for estimating returns, level of beta estimate and structural variations in the market due to stocks and changes in certain company-specific attributes. Our concern here is to test if betas [market risks] significantly affect returns in the Nigerian Capital Market

\section{MODEL SPECIFICATION AND METHODOLOGY}

The CAPM is Expected Security Return = Risk less Return + Beta (Expected Market Risk Premium) written as $E(R)=R f+B(R m-R f)$. Where the risk-free rate $R f$ is the reward for waiting. A risk-free security is one that has a zero variance. Consequently, the covariance between the riskfree security and the risky security will be zero. The risk-free security will have the same return under all possible economic scenarios (Pandey, 1999). Beta is a risk metric employed primarily in the equity markets which measures the systematic risk of a single instrument or an entire portfolio. It is the sensitivity of a stock's return to the return on the market portfolie (Berkley, et al, 2001). Sharpe's work suggests that the expected return on a portfolio should increase proportionally with beta. For example, if a mutual fund has a beta of 1.5 and the expected return on the market increases by 10 percent. and then the expected return on the mutual fund will increase by 15 percent.

The beta measure has two basic characteristics that we to keep in mind during estimation. The first is that it measures the risk added on to a diversified portfolio, rather than total risk. Thus, it is entirely possible for an investment to be high risk, in terms of individual risk, but to be low risk, in terms of market risk. The. second characteristic that all betas share is that they measure the relative risk of an asset, and thus are standardized around one. The reward for bearing risk is the risk premium [Rm - Rf] often proxied by the treasury bill rate. The premium of a security is directly proportional to the risk as measured by beta.

MICROFIT 4.0 statistical software was used to estimate the market risk-return relationship within the Capital Asset Pricing Model $E(R i)=R f+\beta i[E(R m)-R f]$

Where:

$E(R i)=$ ex-post return of securities/industries $\mathbf{R f}=$ risk-free rate (treasury bill. rate)

$\mathrm{Bi}=$ security betas (ex-post security data)

$E(R m)=$ market return (All-Share index)

In estimating the above model we focused on the fourteen (14) most capitalized firms in 2005 Nigerian Stock Exchange Fact book. The firms were NBL, First Bank, Guaranty Bank, Uniliver, Union Bank, UBA, Nestle, NBC, Oando, Total Oil, Cadbury, Conoil and Mobil Oil, while the three industries were banking, petroleum and breweries. The time frame of the study is limited to the period 2001 to 2005 for quarterly data.

\section{EMPIRICAL ANALYSIS}

As stated earlier, the objective of this work is to validate the positive relationship between beta and security returns with the Nigerian Capital Market data. Thus we emphasize the extent to which the Capital Asset Pricing Model (CAPM) can be used to evaluate expected return and risk in the market. The regression results obtained are reported in the Table below. It shows the data for the 14 most capitalized firms and the three (3) most capitalized industry; i.e. their returns and their respective measured market betas. In the table, $R_{i 1}$ to $R_{i 14}$ represent the 14 most capitalized firm and $R$ i1s to $R_{i 17}$ for the three most capitalized industries. 
Table 1: Regression Results fo, the Thirteen Firm and Three Industries

\begin{tabular}{|c|c|c|c|c|c|}
\hline $\begin{array}{l}\text { Dependent } \\
\text { Variables }\end{array}$ & $\begin{array}{l}\text { Independent } \\
\text { Variables }\end{array}$ & Coefficient & t-Statistic & Probability & $\mathrm{R}^{2}$ \\
\hline$R_{11}$ & $\mathrm{~B}_{1}$ & -21.4292 & $-3.4618^{\star *}$ & 0.003 & 0.9757 \\
\hline$R_{12}$ & $\mathrm{~B}_{2}$ & 22.7705 & $2.1383^{\star}$ & 0.047 & 0.8573 \\
\hline$R_{\mathrm{i} 3}$ & $\mathrm{~B}_{3}$ & 24.4296 & $9.0847^{\star \star}$ & 0.000 & 0.7490 \\
\hline$R_{i 4}$ & $B_{4}$ & 21.3515 & $2.3431^{\star}$ & 0.036 & 0.7779 \\
\hline$R_{i 5}$ & $\mathrm{~B}_{5}$ & 26.6954 & $4.4725^{\star *}$ & 0.000 & 0.2639 \\
\hline $\mathbf{R}_{16}$ & $B_{6}$ & 13.2475 & $2.7005^{\star}$ & 0.015 & 0.4975 \\
\hline $\mathbf{R}_{\mathrm{i} 7}$ & $B_{7}$ & $-0.9450^{\circ}$ & -0.7029 & 0.945 & 0.6802 \\
\hline $\mathbf{R}_{\mathrm{i} 8}$ & $B_{8}$ & 8.6080 & 0.5255 & 0.606 & 0.9420 \\
\hline$R_{i 9}$ & $B_{0}$ & 25.8150 & $3.8130^{* *}$ & 0.007 & 0.8846 \\
\hline$R_{i 10}$ & $B_{10}$ & -0.0371 & -0.5177 & 0.611 & 0.9179 \\
\hline$\overline{R_{i 11}}$ & $\overline{B_{11}}$ & -55.4791 & $-2.1452^{*}$ & 0.047 & 0.9398 \\
\hline$R_{112}$ & $B_{12}$ & -16.2379 & $-2.1443^{*}$ & 0.047 & 0.8793 \\
\hline$R_{i 13}$ & $\mathbf{B}_{13}$ & 169.8290 & $4.4506^{* *}$ & 0.000 & 0.9245 \\
\hline$\overline{R_{i 14}}$ & $B_{14}$ & 52.3767 & 0.6512 & 0.524 & 0.6343 \\
\hline$R_{i 15}$ & $\mathbf{B}_{15}$ & -9.1797 & -.0884 & 0.931 & 0.8406 \\
\hline$R_{116}$ & $B_{15}$ & 52.3767 & $1.9512^{\star}$ & 0.052 & 0.7143 \\
\hline$R_{\mathrm{i} 17}$ & $B_{15}$ & 1116.7 & $3.6122^{\star \star *}$ & 0.002 & 0.9059 \\
\hline
\end{tabular}

From table 1 , most of the results confirmed the a priori relationship between beta $[B]$ and security returns [Ri]. Ten out of 14 firms confirmed significant relationship at $5 \%$ level while two out of the three industries also confirmed significant relationships. Moreover, the explanatory power of the model was good; for ten firms, the model had a fit of over $70 \%$. Indeed, only two firms did not describe a fit of above $60 \%$ and the three industries had a fit of over $70 \%$. Only five individual firms and one industry were negatively signed; indicating that majority confirmed a positive linear relationship as expected. For the twelve firms and industries with relationships that are significant at $5 \%$ significant level, only three are negatively signed, probably because they are not actively traded in the market

\section{CONCLUDING STATEMENTS}

In conclusion therefore, empirical evidences significantly indicate that a positive relationship exist between security returns and the measured market betas in the Nigerian Capital market. This implies that CAPM holds in the Nigerian Capital Market. It confirms the results of studies such as Brailford and Josev (1997), Fama and French (2003) which indicated a linear relationship between returns and betas of portfolio.

Based on the finding from the study, we recommend

- that investors and portfolio managers must accommodate portfolio optimization as the market significantly rewards market risk;

- that firms and industries must be proactive in diversifying non-systematic risks and creatively responding to market risk; and

- that effective economic policies are required to continue to enhance the sovereign risk status of the country as well as that of the firms and industries:

\section{REFERENCES}

Berkley, R. A., Myers, S. C. and Marcus, A. J., 2001 Fundamental of Corporate Finance. Third Edition, McGraw-Hill Irwin, Boston.

Brailsford, T. J. and Josev, T, 1997. "The impact of return interval on the estimation of systematic risk", PacificBasin Finance Journal, 5, pp $357-376$

Burton, J., 1998. "Revisiting the Capital Asset Pricing Model", Dow Asset Manager, May/June 1998, Pp. 20-28.

Elton, J. E. and Gruber, M. J., 1997. Modern Portfolio Theory and Investment Analysis, Fifth Edition, Singapore, Wiley \& Sons Pte Ltd.
Fama, F. E. and French, R. K., 2003. "The Capital Asset Pricing Model: Theory and Evidence", www.ssrn.com.

Kerr, E., 1997. "Capital Asset Pricing model- Basic Concepts", in Financial Management Study Notes, $21^{\text {st }}$ April, 2006. C: Mine in FlashlCAPMlek422.htm

Kevin, S., 2001. Portfolio Management, Prentice Hall, New Delhi.

Lintner, J., 1965. "The Valuation of Risk Assets and the Selection of Risky Investments in Stock Portfolios and Capital Budgets", Review of Economics and Statistics, 47 Pp 13-37.

Markowitz, $H ., 1952$. "Pontfolio selection", The Journal of finance, 7, (1): March, Pp 77-91, American Finance Association

Moine, D., 2004. "Cracks in the Asset Allocation Model", 23rd June, 2006, http://advisor.morningstar.com

Pandey, I. M., 1999. Financial Management. Eighth Edition, Vikas Publishing, Delhi.

Osaze, E. B., 2000. The Nigerian Capital Market in the African and Global Financial System, Bofic Consulting Group Limited, Benin-City

Riskglossary, 2006. "Capital Asset Pricing Model", unw.riskglossary.com mww.contingencyanalysis.com

Sharpe W. F., 1964. "Capital Asset Prices: A Theory of Market Equilibrium under Conditions of Risk", Joumal of Finance, 19, (3): Pp 425-442.

Tobin, James, 1958. "Liquidity Preference as Behaviour towards Risk", The Review of Economic Studies, 25 Pp65-86.

UW Showcase, 1997. "Capital Asset Pricing Model (CAPM)" 21th April, 2006). C:lMine in FlashiCAPMlcapital_.htm

Sharpe W.F., Linter J. and Treynor, 2006. "CAPM- Capital Asset Pricing Model", E:ICAPMImethods_capm.htm.

Van Horne, J. C., 2004. Financial Management and Policy, Twelfth Edition, Prentice-Hall of India, New Delhi. 